\title{
Border blocking effects in collaborative firm innovation
}

\section{Exploring the factors related with scientists' willingness to incorporating external knowledge}

\section{CHEPS WORKING PAPER 02/2016}

Jos van den Broek. Radboud University Nijmegen and European and Regional Affairs Consultants

(ERAC), 's-Hertogenbosch.

Josvandenbroek@erac.nl

Paul Benneworth. CHEPS (University of Twente)

p.benneworth@utwente.nl

Roel Rutten. Tilburg School of Social and Behavioural Sciences (Tilburg University)

R.P.J.H.Rutten@uvt.nl

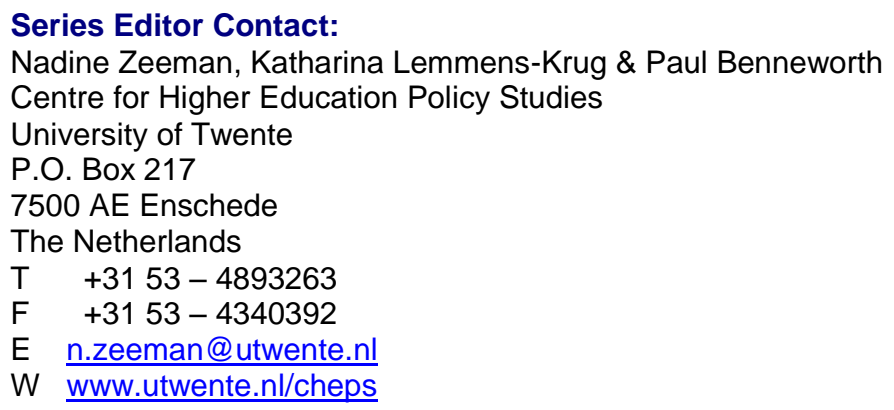




\section{Table of Contents}

Introduction ... 


\begin{abstract}
Border regions are not often associated with innovation and economic prosperity. Nevertheless, the opening up of borders in Europe has presented new opportunities for firms located in these border regions to co-operate and find necessary resources for their innovation process. Despite the reduction of the importance of borders, firms seeking to access those resources need still 'cross' the border and address the various effects it brings. This paper therefore asks the question of how the presence of a border affects the processes by which firms attempt to build up productive co-operations for innovation. We stylise inter-firm innovation across borders as building up through four sequential stages cooperation in four stages, and each of these different stages are susceptible to different kinds of border effects. Using a case study of firms co-operating across the Dutch-Flemish border, we empirically explore these border crossing processes in order to shed further light on how border processes play out.
\end{abstract}

Key words: Borders, Dutch-Flemish border region, case study, innovation, collaboration, firms. 


\section{Introduction}

Border regions raise a clear dilemma for policy makers. They are often apparently weakly performing regions with relatively low wealth levels. They may lack dynamic hightechnology industries, be remote in terms of distance from national core regions, and often suffer from a lack of central government policy attention (Haselsberger \& Benneworth, 2011; Lofgren, 2008). But despite these peripherality problems, it is surprising that they do not seek to compensate for this remoteness by building linkages with other similar regions immediately across their borders. More specifically, given the increasing importance of innovation to regional economic success (Moulaert \& Sekia, 2003) and the fact that border regions often host the fewest innovation resources 1 , developing cross-border regional innovation connections may provide a mechanism to improve border regions' innovative capacity and competitiveness (Trippl, 2010). But most policy and academic interest in cross-border co-operation to date has explored institutional and political co-operation, with little consideration of co-operation between firms seeking to innovate (Leick, 2012).

A duality in the idea of border (Van Houtum, 1998) creates ambiguity in understanding how it may impact on innovation. Innovating firms need a wide range of knowledge inputs, financial and human resources, skills, facilities and market knowledge (Fagerberg, 2006). A border may be a gateway beyond which actors may encounter new resources for innovation (hence positive). However, it can also be a barrier that hinders actors in interacting and exchanging resources (thus negative). Of course, a real border may see both processes functioning simultaneously, making it further harder to precisely determine how a border affects material and symbolic practices associated with innovation (Van Houtum, Kramsch, \& Zierhofer, 2005).

The formal removal of borders between countries in the European Schengen area has not removed the influence of borders on people's and firms' behaviour (Paasi \& Prokkolo, 2008). Yet, clearly, the opening of borders has offered new chances and opportunities for innovating firms. This net effects - and the extent to which cross-border innovation networks and systems have emerged - remains emergent, with very successful cross-

\footnotetext{
${ }^{1}$ With the honourable and well-known exceptions of the Öresund and Eindhoven-Leuven-Aachen regions (Cf. OECD, 2013).
} 
border innovation regions indeed existing (OECD, 2013). But these are often core regions in a country, such as Eindhoven in the Netherlands or Copenhagen in Denmark; for crossborder regions lacking such strength, there is a double bind - a general absence of innovative firms and relatively limited resources for innovation.

Patent data highlights that firms in regions divided by a border are only as likely to cite each other's patents as they are with firms in any other region globally, whilst far more likely to cite patents from firms within their own national borders (OECD, 2013), further suggesting that national borders remain important barriers to innovation. Nevertheless, even in weaker border regions, there are firms that have found ways to deal with problems related to cross-border collaboration, purposively or non-purposively (Krätke, 1999).

This paper therefore asks the overall research question of how the presence of a border affects the processes by which firms attempt to build up productive co-operations for innovation. We conceptualise here the process of innovative border crossing using Koen's (2011) model which understands co-operation as progressing through four stages, the decision to co-operate, partner identification, co-operation formalisation and innovation co-operation. Drawing on an example of firms co-operating in innovation across the Dutch-Flemish border, we develop and test a series of propositions on how a border may affect innovation processes.

\section{Conceptualising border effects on collaborative innovation processes}

\section{Understanding collaborative firm innovation as a process}

We here stylise innovation as a process around two key properties, namely that it can be understood as a systemic process (Fagerberg, 2006) and also that it is dependent on interactive learning both within and outside the firm (Revilla Diez \& Kiese, 2009). From this perspective, innovation involves exchanging knowledge between actors: some of the exchanged knowledge is at least partly non-codified knowledge, which requires more interactive, social exchange processes (Nelson \& Winter, 1982). Regular (repeated) interactions and the sharing of both tangible and intangible elements of knowledge provides the basis of collaborative innovation, often characterised by uncertainty and complexity (Bathelt \& Turi, 2011). Firm capacity to transfer knowledge depends on inter- 
actor social connections and proximity (including temporary proximity or co-location). There is a learning curve - knowledge exchange transactions between two actors become increasingly easier over time (Bathelt \& Turi, 2011; Gertner et al., 2011; Torre, 2008). Knowledge flows more easily in networks of already interacting actors (Uzzi, 1997), and over time, those knowledge networks may acquire their own autonomous dynamics, which may be understood as recurrent, systemic properties (Amin \& Cohendet, 2004).

This 'systemness' is in part derived from the fact that knowledge creation requires knowledge acquisition from outside the business and that regular linkages ('systems connections') accelerate (and consequently reduce the cost)that process of external knowledge acquisition (Grant, 2002). The complexity of innovation projects, the pressure on the time to market and the high cost of technological development makes it difficult for firms to generate all the necessary resources entirely internally (Barney \& Clark, 2007; Marshall et. al., 2007). Effective innovation therefore depends on firms capacities' to develop collaborative arrangements providing access to such complementary innovation resources (Hassink \& Klaerding, 2012; Knoben \& Oerlemans, 2012).

Collaborative innovation is understood as a learning process aiming at developing a new product, process or technique between two or more firms. Collaborative innovation is positively influenced by higher degrees of relative absorptive capacity, relational routines, cross-border experience and relational capital (Dyer \& Singh, 1998; Kale et.al., 2000; Kim \& Inkpen, 2005). Trust positively influences the accessibility of knowledge, relationship formation and knowledge exchange (Nielsen, 2004) and its development between partners is crucial for successful collaboration.

Although much literature considers the innovation element of collaborative innovation, there is much less literature considering the dynamics of co-operation, by which firms build up linkages to other firms to provide capacity to mutually exchange knowledge resources in innovation activities. Both Marxt \& Link (2002) and Koen (2011) have conceptualised this collaboration process in terms of staged models, each involving four (cognate) stages. Marxt \& Link (2002) distinguish "initiation", "partner selection", "setup" and "realisation", whilst Koen (2011) distinguished "need", "find", "formalize" and "execute" phases. Although couched in different languages, what both categorisations highlight is that for each phase there is qualitatively different extent to which the outside world intrudes in the process. In the first phase it is entirely absent, in the second there 
are possibilities for interaction, in the third, there is a concrete partner with whom links are being developed, and finally, attempts are made to exchange knowledge resources with that partner. We combine these two into our model of how firms experience collaboration in collaborative innovation (see figure 1 below). From our perspective:

- The initiation stage involves a firm making a decision to engage in collaborative innovation instead of in-house innovation.

- The partner selection stage involves finding a partner with both useful complementary assets and the ability to develop linkages with the firm.

- The collaboration stage (Marxt \& Link, 2002) involves formalizing the agreement (Koen, 2011), regarding the formal and administrative procedures relating to a project.

- The execution stage involves the process of exchanging knowledge resources to create new innovations.

Figure 1: The four-stage collaborative innovation process (adapted from Marxt \& Link, 2002)

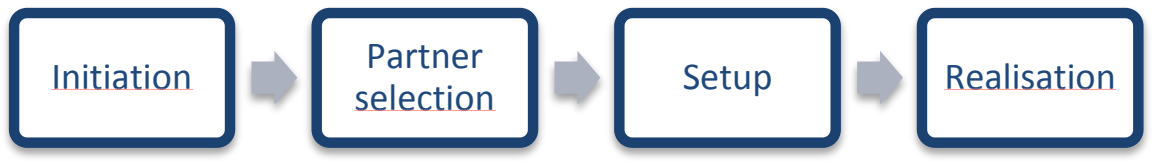

\section{Barriers associated with cross-border innovation}

To better understand the negative border effects on collaborative innovation, we therefore seek to examine more systematically the kinds of barriers a border might raise for each of these stages of collaborative innovation. In general terms, there are three ways in which the presence of a border might negatively impact upon social knowledge exchanges processes, in terms of their network effects, cross cultural differences and different juridical and administrative systems. Firstly, contact networks may end at the border for many firms, especially SMEs. Innovating firms have often built up a network of contacts with whom they have prior interaction and co-operation, giving them confidence that material co-operation with those firms might be successful, as well as the chance to explore via their contacts whether their second-order contacts (their contacts' contacts) might also be good partners. The border thus separates the firms from an "unknown and insecure environment" (Koschatzky, 2000; 446) of the cross-border 
region. When working across borders, SMEs prefer to invest their scarce resources into less risky trade contracts (Leick, 2012).

A second barrier associated with cross-border collaborative innovation are cross-cultural differences that hinder mutual understanding and comprehensibility. Language is the most notable difference in this regard and SMEs may disproportionately experience this barrier as their small size reduces the probability that one of the employees may speak that foreign language sufficiently fluently (Hahn, 2013; Koschatzky, 2000). But it is not just language barriers that exist - differences in mentality, mind-set and business practices act as a possible cooperation barrier (Leick, 2012), because, as Stensheim (2012; 663) puts it:

Job-related behaviour and attitudes, industry culture, communication, power and/or hierarchy and gender relations are aspects, which are institutionalized and often associated with clear dividing lines between cultures or nations.

The third barrier is related to the differences in juridical and administrative systems (Haselsberger \& Benneworth, 2011). The influence of the border can manifest itself in differing tax systems, social security systems, legislation and vocational training systems (Klatt \& Herrmann, 2011), all of which affect the ways in which firms understand innovation and seek to organise it to maximise its efficiency. Alongside these indirect effects, there can be direct effects across a border with different funding opportunities and fiscal regimes for innovation and R\&D in different countries, that may lead to partners pursuing different incentives and having different attitudes and approaches to research, development and innovation activities.

\section{Barriers associated with the stages of collaboration development}

Applying this to our stage model of collaborative innovation, we see that each effect may play out in different ways at each process stage as the challenge shifts from identifying any potential partner to working with one particular partner(Marxt \& Link, 2002). Each of the four stages has its own dynamics, and the role and influence of the border may differ per stage. Given that these phases appear to be qualitatively different, we contend that the kinds of border barriers that firms may experience at each phase may be different. For firms that do not know any potential co-operation partners, the border is a line of 
uncertainty beyond which little may be known. For firms that are already exchanging knowledge, then border barrier effects may be much more imminent, related to the different kinds of symbolic and material practices prevalent across each side of the border.

Answering our overall research question of how the presence of a border affects collaborative innovations therefore requires us to consider how these effects differ across the different stages of collaborative innovation. In so choosing to do, the firm signals that a particular calculus has been made between the two kinds of border effect, that is that the rewards (resources) are worth the efforts (working across a barrier). In each phase, firms see reaching over the border as a way of accessing unique resources not readily locally accessible, but what makes it worthwhile as well as difficult differs between phases.

In the first stage there should be a clear need for collaboration, in this stage cross-border collaboration adds an extra complexity and is only necessary where there are no comparable collaborators in the region. The initiation stage will most likely not be substantially different for firms engaging in cross-border collaborative innovation. As innovation is already an uncertain and complex process, engaging in any kind of collaborative innovation adds extra complexity (Koen, 2011). In the fourth execution stage, differences in cultures, ways of doing things and language barriers may be hurdles that need to be addressed.

In the table below, we set out in more detail how these border influences may differ between the four phases of cross-border innovation, and the different reasons that firms have for looking across the border at each phase. In the first phase, the calculus is a choice between beginning to look over the border or not, in the second looking where the firm does not have ready networks, in the third deciding whether a partner might be suitable and then finally attempting to make the collaboration and knowledge exchange work. Our propositions (with the link to the relevant literature) are set out in table 1. 
Table 1: Postulating the border effect

\begin{tabular}{|c|c|c|c|}
\hline & Literature & $\begin{array}{l}\text { Cross-border } \\
\text { perspective }\end{array}$ & Propositions \\
\hline 1. Initiation & $\begin{array}{l}\text { Consider why engage } \\
\text { in collaborative } \\
\text { innovation instead of } \\
\text { in-house innovation } \\
\text { (Koen, 2011). Unique } \\
\text { assets needed. }\end{array}$ & $\begin{array}{l}\text { Cross-border } \\
\text { collaboration adds } \\
\text { extra dimension of } \\
\text { difficulty and risk to } \\
\text { already uncertain and } \\
\text { complex process. }\end{array}$ & $\begin{array}{l}\text { Firms only cooperate } \\
\text { cross-border when } \\
\text { there are no national } \\
\text { alternatives }\end{array}$ \\
\hline $\begin{array}{l}\text { 2. Partner } \\
\text { selection }\end{array}$ & $\begin{array}{l}\text { Search process mostly } \\
\text { starts with nearby } \\
\text { partners: own } \\
\text { collaborators. } \\
\text { Information on } \\
\text { possible collaborators } \\
\text { is important. (Marxt \& } \\
\text { Link, 2002) }\end{array}$ & $\begin{array}{l}\text { Firms (in border } \\
\text { regions) are nationally } \\
\text { oriented when } \\
\text { searching partner (Van } \\
\text { Houtum, 1998; Trippl, } \\
2010) .\end{array}$ & $\begin{array}{l}\text { Firms, especially } \\
\text { SME's, lack knowledge } \\
\text { about potential } \\
\text { partners on the other } \\
\text { side of the border, } \\
\text { hindering the partner } \\
\text { selection process. }\end{array}$ \\
\hline 3. Setup & $\begin{array}{l}\text { Formal agreements } \\
\text { about the } \\
\text { collaboration are } \\
\text { necessary } \\
\begin{array}{l}\text { (Ko11). } \\
\text { Koen, }\end{array}\end{array}$ & $\begin{array}{l}\text { Formal agreements } \\
\text { and administrative } \\
\text { procedures differ and } \\
\text { there are extra } \\
\text { administrative } \\
\text { procedures in cross- } \\
\text { border cooperation. }\end{array}$ & $\begin{array}{l}\text { Formal and } \\
\text { administrative } \\
\text { differences hinder the } \\
\text { setup and realisation } \\
\text { of the collaborative } \\
\text { innovation process. }\end{array}$ \\
\hline 4. Realisation & $\begin{array}{l}\text { Collaborative } \\
\text { innovation requires a } \\
\text { high degree of trust } \\
\text { and absorptive } \\
\text { capacity. }\end{array}$ & $\begin{array}{l}\text { Different epistemic } \\
\text { communities on } \\
\text { different sides of the } \\
\text { border lead to different } \\
\text { modes of operation. }\end{array}$ & $\begin{array}{l}\text { Although epistemic } \\
\text { communities differ, } \\
\text { cognitive proximity } \\
\text { can as bridging } \\
\text { mechanism. }\end{array}$ \\
\hline
\end{tabular}

\section{The "Crossroads" project and the Dutch - Flemish border region}

\section{Introduction to the case study region}

We address our research question by exploring these four propositions using a single case study, the Dutch - Flemish border region (see map 1 below). In this region, there is a strong presence of manufacturing firms, mainly small and medium-sized firms (SMEs), 
who are working as suppliers of OEMs (Original Equipment Manufacturers) such as Philips, ASML and Janssen Pharmaceutica. The region consists of the Dutch provinces of Zeeland, North Brabant and Limburg, and the Flemish provinces of Antwerp, Flemish Brabant, Limburg, East Flanders and West Flanders. There is much high-tech manufacturing in this region, clustered in the co-called "Top Technology Region Eindhoven-Leuven-Aachen triangle "(TTR-ELAt), and also around Antwerp; both regions have seen much co-operation between firms, government and knowledge institutes (OECD, 2013). Despite this, strong potential for cross-border innovation in the region's strong sectors appears to have failed to evolve into dense networks of cross-border linkages.

One initiative to strengthen these linkages in the region is the "Crossroads" project. The Crossroads project is the first funding scheme aimed directly at collaborating SMEs, and part of it is a funding scheme for collaborating SMEs in six high-potential regional sectors: embedded vision, remote diagnostics, nano-materials, inkjet technology, and surface treatment and materials. Participating firms received a maximum subsidy of $50 \%$ for joint innovative projects; 21 collaborative innovation projects were developed among firms, of which two failed. Most projects contained two partners, one on each side of the border. The project received $€ 3 \mathrm{~m}$ from the INTERREG IVA programme Flanders - Netherlands, financed by the European Regional Development Fund. This programme is designed to stimulate cooperation in Europe's border regions, and nearly half its budget is directed towards cross-border innovation and entrepreneurship. 


\section{Figure 2 The Flemish-Dutch border region}

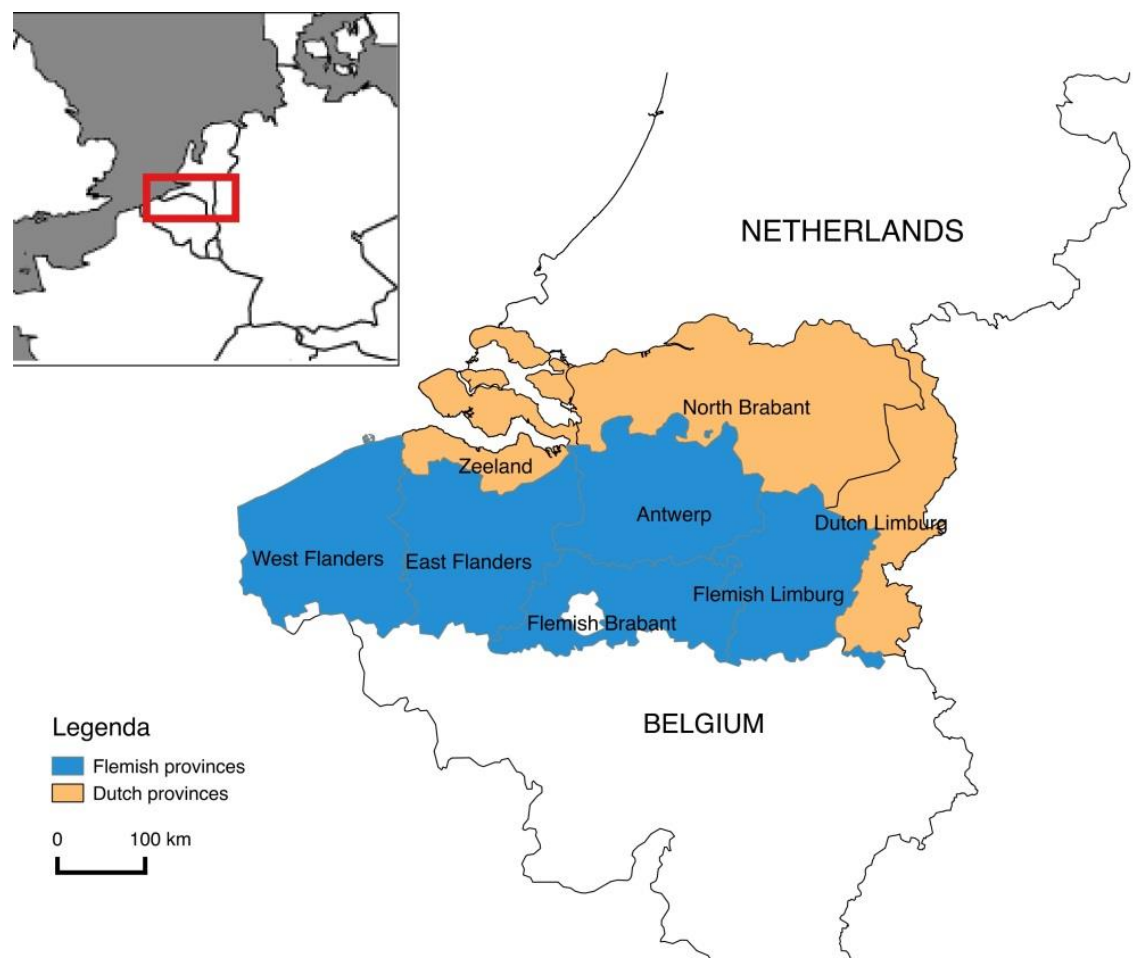

\section{Research methods}

In our research, we explored the role of the border on the cross-border innovation practices of Crossroads participants, to provide more detail on the way that bordering processes operated as innovating firms built up innovation collaboration, and to nuance our propositions. For this reason a qualitative approach was chosen using semistructured interviews, supplemented with the Crossroads project plan alongside and project information accessed via a Crossroads brochure and the project website. Crossroads was chosen as a means to easily identify firms engaged in cross-border cooperation, and of the 21 projects underway provided potential access to more than 40 collaborating companies. The firm list was drawn up from the project brochure and website, and the responsible individual in each company was identified and approached by email and telephone. Of the 19 successful innovation projects within Crossroads we were able to speak to 13 and conducted a total of 15 interviews.

The interviews were undertaken with the person responsible for collaborating and interacting with their foreign partner, and because our sample was mainly of small firms, this was usually a director, although in four cases we spoke with a project manager or 
chief engineer. Interviews lasted between 45 and 120 minutes and were all taped and transcribed. The interviews followed a semi-structured protocol, with prompts grouped around three topics: the innovation itself, the cooperation decision and search process and the cooperation process. The protocol allowed cross-case comparisons with each interviewee providing responses covering similar topics, whilst also permitting interviewees to place emphasis and talk about the issues and perspectives of greatest personal concern.

\section{Developing cross-border innovation contacts in the Crossroads project}

\section{Barriers to co-operation in firms initiating co-operation}

In the initiation phase we see that the border was almost completely absent from firms' considerations, which relate in the first instance primarily to whether the firm needs to access external resources in order to collaborate, given their own particular approaches to innovation. It was only in when selecting partners that partner location came to play a role, as part of the innovator's attempts to determine whether a partner can be regarded as a competent collaboration partner.

In our cases we observed that the reported reasons for choosing to co-operate could be distinguished between those that were synoptic, and those that were opportunistic. Some firms reported opportunistic reasons for cooperation, and in these cases there was no a priori innovation problem in response to which they initiated a partner search: they met someone, for example at a conference or exposition and then picked up the idea to start cooperating. Being small and medium sized companies their resources for innovation are limited. The access to financial resources, the subsidy, was important for most firms.

Firms with more intrinsic reasons for cooperation had a clear need for an external resource, and actively decided to search for this external resource, choosing for crossborder search following a synoptic process of weighing up the choices on offer in terms of their costs and benefits. Three types of rational reasons can be distilled from the interviews, which can be seen as the most important and crucial rational reasons for cooperation. These are knowledge access, market access and subsidy access. 
First, almost all firms with rational reasons for cooperation experienced a knowledge gap. One firm mentioned the need to integrate several components on one print board, and doing that effectively required both knowledge and machinery that they did not have nor could they secure in their immediate environment. This could be knowledge about the workings of specific components, knowledge about integration of components or knowledge about specific technique that were needed to successfully innovate. This can be illustrated by the observation of one of the firms, who states that "at some moment in time you reach the limits of your own stints".

Second, market access can be access to a new market or to the same market in a different country. Another firm put forward their need to access a new market segment because they observed that they did not have a product for a crucial part of the control chain. Their main product was a static measurement system and in order to fulfil their customers' needs they needed a dynamic, handheld measurement system. But it can also mean that via cooperation partner the innovation becomes affordable for an end customer. For example a vision technology of one firm can hardly be afforded by one end customer, but through the cooperation the costs can be spread over several end customers because the cooperation partner is a systems integrator offering total solution to end customers. This firm states that "what we developed now would have never been possible on our own". Stand-alone there was no market for this innovation, but now there is a huge market because they cooperated with a large player.

Third, several firms stated that without the financial support from the funding scheme the innovation would have been delayed or not have been developed at all, as one of them states: "Investing 50.000 - 100.000 euros is very hard for an SME. That was a very difficult barrier to overcome without the subsidy". The three kinds of synoptic reasons for cooperation all point to the fact that firms lacked a unique and crucial resource for their innovation to succeed. In their decision to initiate a collaborative innovation project and search for knowledge-, market- or subsidy access their first decision was to search for a partner, not for a cross-border partner per se.

\section{Barriers to co-operation in partmer selection}

Although most firms stated that they were looking for the "right" knowledge, they started their partner search processes initially in their direct surroundings, meaning in this case their nationally demarcated region. Only when a firm became convinced there was no 
immediately accessible local partner was the search extended. For some this directly meant searching globally, in whatever location. Most other firms in our sample found a partner directly across the border (clearly a consequence of our sample). Although this mostly led to a successful cooperation and the firms mostly were positive towards doing another collaborative process with the same partner, they also stated that for a different innovation question they would again have difficulties finding a partner on the other side of the border. It would however be easier for them to work across the border after a first experience with it.

The firms that had rational reasons for cooperation started searching for a partner after the decision was made to initiate a collaborative innovation project. The firms mostly first looked in their own networks for a partner. When no partner was directly accessible in their networks they moved on to look with a broader scope, thereby pursuing different search strategies. In general all firms that we spoke to indicated that they lack knowledge of potential collaboration partners on the other side of the border.

In this phase a broad distinction can be made between those firms that already knew their partner and those firms that did not, the firms that already knew their partner having crossed the border at an earlier moment in time. Crossing the border for the first time can be understood as changing the role of the border qualitatively for a firm a boundary (beyond which there is unknown terra nulla) into a gateway to access novel resources. Of those firms who had 'crossed borders' prior to Crossroads, some already had experience with cross-border working, whilst others only knew their partner by name or as a competitor or subcontractor. Our contention is that the border effect in partner selection is likely to be very different for firms that have 'crossed borders' in terms of the event that stimulates border crossing, the search processes they use and their rationales for crossborder searches.

Firstly, the firms that did not previously know their partner tended to search in the first instance in their direct surroundings (their own region and country). Even a single firm may see crossing the border as advantageous for bringing many kinds of advantages simultaneously, as one Flemish firm from Leuven noted: 
"... you start to know people, their ways of doing and get to know the firms. The fact that they [firms in the regional network] are close by makes contact easier, especially in a development project".

Secondly, there were a range of strategies used by firms in their partner search processes. Some used approaches more based on codified knowledge, looking through directories to identify a partner with the required knowledge. Others sought a social approach, physically going to the places where potential partners might be, such as conferences and network meetings. Yet other firms used approaches for searching for partners based on their tacit knowledge (know-how and know-who), turning to other partners and subcontractors, the BOM (a regional development agency) and DSP Valley (a regional cluster organization). One of the firms argued:

"we then [after searching inside the region] had to look further, we skimmed the Internet. Via another network (...) we came into contact with [our partner].

Thirdly, although most firms searched for a partner with unique knowledge or market access, some firms specifically searched for a Flemish or Dutch partner in order to fulfil the funding scheme criteria, and access the financial resource of the subsidy. For example two Dutch partners searched for a Flemish partner to get subsidy access because "you needed a foreign [Flemish] partner, so we went looking for one". Other firms said they looked for firms with the critical competences needed, and it was a coincidence that this firm was located in the Netherlands or Flanders.

Firms that already knew their partner had in common that they did not have a wide network over the border, and their contact was an isolated example, and therefore their co-operation over the border was shaped by these pre-existing contacts. A particular issue here was the difficulty this posed for accessing firms with complementary knowledge for innovation: although they knew many foreign competitors and suppliers, they did not know firms with knowledge that fitted well with their own in terms of shared innovation processes.

\section{Barriers to co-operation in project setup}

Once a suitable partner was located, the next activity firm will undertake is project setup, when a project is designed and developed. This is a period of prospective planning, when agreements are made in principle seeking o guide the future collaboration, to 
balance out interests and guarantee that the co-operation will be productive partnership. There are two main components to these discussions - some are related to administrative and practical issues ('how to co-operate') and others towards content issues ('what to innovate'), although in practice these two elements were found to be interrelated.

The subsidy rules were perhaps not unsurprisingly an important aspect of the administrative negotiations in establishing projects rules. Although most of the firms experienced administrative tasks as being bureaucratic and time consuming, this was not specific to a border situation: the border did not materially appear to affect the level of bureaucracy. The practical difficulties that the border raised were primarily around administrative hindrances, and firms that co-operated cross-border for the first time experienced a range of differences. There were for example differences in the use of VAT, differences in the way employees were contracted and differences in certification. However, most firms did not really experience difficulties regarding rules and regulations. Most of the certification and regulations were Europe wide; although there were some differences in the way a European rule is interpreted. One example a firm gave was vehicle certification, regulated by the EU. A certification granted in one European country is certified in all European countries, although the requirements for certification do vary nationally. The rules in Flanders are much harder to fulfil than in Netherlands, and therefore the firm planned to arrange certification in the Netherlands. All of the firms crossing the border for the first time reported having learned a lot from their project in administrative terms and thought it would be much easier a next time.

These issues were also salient for those firms that were already experienced in setting up collaborative projects over borders. However, that previous experience had provided them with the repertoire to address them; rather than being a barrier to full co-operation, practised firms experienced these as a precondition, which had to be dealt with. As one of these firms stated, providing a specific example of that how the differences in regulations were not a purely administrative construct, but reflected real differences across borders:

"Our [products] have to work for a specific customer. (...) We do not built [a product] to comply with regulations, we built [a product] that works for our customer." 
The differences in administrative and practical issues were present for all firms. Although we can observe that firms with experience dealt with these issues with more ease, the first timers learned quickly and these differences did not lead to serious problems for the innovation projects.

\section{Barriers to co-operation in the realisation phase}

All the firms we talked to agreed that in the execution of the project there were hardly any differences between a cross-border innovation project and a project with domestic partners: innovation is always a difficult process. In the first instance, all were aware that they were co-operating with a foreign company. Almost all firms divided the project up into separate work packages under the leadership of one team member. Typically the firms met a few times in the setup phase of the project, and one or two times during the project to discuss problems and issues arising within their work packages, but separated responsibilities and restricted co-operation to a minimum within the individual work packages:

"we worked separately on the project, only communicating by e-mail. We have separated [the tasks] on purpose, and this was possible here. Then it is an advantage that you speak the same language, as you could easily speak over the phone."

In the actual implementation phase, the partners experienced differences, although most of those are typical problems in co-operative innovation to which it is hard to ascribe a particular cross-border dimension. A recurrent theme in the interviews was a perception that there was a 'cultural difference'. This was articulated by some interviewees in language such as the directness of the Dutch in comparison to the Flemish partners, differences in working hours (Dutch work less fulltime), differences in number of meetings and consultations between managers and employees (the Dutch use of meetings to punctuate decision-making), and also subtle difference between Netherlands-Dutch and Flemish-Dutch. But this was not always perceived as a problem, even if it was a difference: one of the Flemish firms reported of a Dutch partner that did not their a user interface "they [the Dutch customer] simply say: that one is ugly. Make us another one". That directness was highly appreciated by the Flemish partner, because in their yes it speeded up and made more transparent the cooperation and decision process. 
Next to these cultural differences, there were also some technical differences, and in the context of the firms interviewed, a recurrent problem was that of the electrical infrastructure. The Netherlands and Belgium are superficially different in terms of having different power sockets (a common sort of Dutch plug socket is illegal in Belgium). Perhaps more importantly, maximum supply voltage varies between countries, and whilst it is diurnally stable in the Netherlands, voltage in Belgium is higher during the day than at night. First, firms need to be aware of this difference, which is not self-evident. Second, the product has to be adjusted to this because otherwise: "all the fuses melt... [and] ...one of the things customers demand is to use the product in their country". However, this is not an exclusively border issue as all firms that develop innovations for the international market have to deal with this. Indeed firms in the first instance do not see many differences between cooperating cross-border and cooperating with domestic partners, but that they did have to cope with some, mostly subtle, differences.

\section{Analysing border blocking effects by phase}

Based on the literature on collaborative innovation and the possible barrier effect of the border we have developed four propositions, one for each stage of the collaborative innovation process. The results of our exploratory case study show that three out of four of the developed propositions hold for most of the firms, whilst there are always exceptions. On the basis of the interviews in the case study, it appears that the role of the border differs across all four stages of the collaborative innovation process (see Table 2 below). There is also an observable difference between firms who are 'crossing borders' for the first time and those that have more experience in dealing with the challenges the border poses for collaborative innovation.

\section{Table 2 Observed border blocking effects}

\begin{tabular}{|lll|}
\hline 1. Initiation & $\begin{array}{l}\text { Propositions } \\
\text { Firms only cooperate cross- } \\
\text { border when there are no }\end{array}$ & $\begin{array}{l}\text { The rational reasons for cooperation point to } \\
\text { national alternatives }\end{array}$ \\
& $\begin{array}{l}\text { the fact that firms lacked a unique and crucial } \\
\text { resource for their innovation to succeed. }\end{array}$ \\
& $\begin{array}{l}\text { The first decision is to search for a partner, } \\
\text { not for a cross-border partner per se. }\end{array}$ \\
\hline
\end{tabular}




\begin{tabular}{|c|c|c|}
\hline & & $\begin{array}{l}\text { - Firms first look in their local and national } \\
\text { networks for a partner. }\end{array}$ \\
\hline 2. Partner selection & $\begin{array}{l}\text { Firms, especially SME's, lack } \\
\text { knowledge about potential } \\
\text { partners on the other side of } \\
\text { the border, hindering the } \\
\text { partner selection process. }\end{array}$ & $\begin{array}{l}\text { - Firms lack knowledge of potential } \\
\text { collaboration partners on the other side of the } \\
\text { border. } \\
\text { - Especially when it comes to partners with } \\
\text { knowledge outside their own core } \\
\text { competence. }\end{array}$ \\
\hline 3. Setup & $\begin{array}{l}\text { Formal and administrative } \\
\text { differences hinder the setup } \\
\text { and realisation of the } \\
\text { collaborative innovation } \\
\text { process. }\end{array}$ & $\begin{array}{l}\text { - All firms experienced administrative and } \\
\text { practical differences } \\
\text { - } \text { Earlier experience with these differences } \\
\text { leads to learning effects. } \\
\text { - The collaborative innovation process was not } \\
\text { seriously hindered by these differences. }\end{array}$ \\
\hline 4. Realisation & $\begin{array}{l}\text { Although } \quad \text { epistemic } \\
\text { communities differ, } \\
\text { cognitive proximity can as } \\
\text { bridging mechanism. }\end{array}$ & $\begin{array}{l}\text { - Main problems that are experienced are } \\
\text { "regular" innovation problems. } \\
\text { - Small and subtle differences hardly lead to } \\
\text { problems. }\end{array}$ \\
\hline
\end{tabular}

For the first proposition - Firms only cooperate cross-border when there are no national alternatives - we found that most firms indeed first searched for national, mostly regional, partners within their existing networks. Only when they could not find a suitable partner in their direct surroundings were they stimulated to look for a distant partner. But this partner was not necessarily automatically located by preference just over the border, as it could be located anywhere in the world or within Europe. Firms that directly looked for the best available partner globally were those that already had extensive experience in locating and working with foreign partners.

In this stage of the process of building up a cross-border co-operation, firms are making an internal-external decision, and in the case that they choose to go externally, they then proceed to the second phase, partner selection. The nature of the border in the first phase is in line with our proposition, in that it is completely opaque to firms that have not yet crossed the border. For those that have, their primary consideration is whether they already know of firms over the border who may be able to provide the complementary resources they require. This has a substantial damping effect on spill-overs which rely on spontaneous contact and interaction between firms not yet in contact but with the potential to mutually profit from interaction. 
This substantial damping effect is related to our findings regarding the second proposition: Firms, especially SMEs, lack knowledge about potential partners on the other side of the border, hindering the partner selection process. There were some firms that had earlier connections that they could use to find a partner on the other side of the border. However, most firms needed help, which could come from within their network of suppliers and customers, but also came from RDAs, Chambers of Commerce and cluster organizations. The firms had in general good knowledge about their competitors, whether they are close to them or on the other side of the globe. However, these firms are not the most likely cooperation partners. As they are engaging in an innovation process and look for knowledge that they do not have, they need access to networks of firms that are often unfamiliar for them.

The border effect here can be considered as distanciating firms from geographically proximate partners. Firms deciding to co-operate who choose not to work with existing known partners have to embark on a search process, and this search process is guided at best by bounded rationality. The border here functions by further bounding that rationality - although this is not an absolute effect, rather it adds additional friction to the likelihood of a particular 'good enough' search process locating a firm immediately over the border before an acceptable set of alternatives have been identified. Cross-border innovation is not necessarily undesirable for these firms, but rather it is rarely perceived as being a realistic option and therefore not substantially engaged with.

Our exploratory study suggests that the third proposition - Formal and administrative differences hinder the setup and realisation of the collaborative innovation process - does not hold. Firms did experience some difficulties related to administration and formal aspects of the cross-border collaboration. For some this has led to serious investments in terms of time and money. Nonetheless, in none of these cases did this really hinder the setup and realisation of the collaborative innovation project. Firms mostly saw the extra costs they had to make as investments in future profitable collaborative activity. There was also a tendency to plan the project activities in separate work-packages split between the partners, operating on one or other side of the border. There is a question of whether this is a true border effect or one of purely administrative simplicity. There are potential opportunity costs for the firms in separate work packages minimising interactive learning 
opportunities and therefore undermining the development of shared contextual knowledge resources.

The border effect on this third phase, establishing concrete projects, is to introduce a segmentation within the innovating community, something which can be thought of as representing a structural hole in the firms' innovation network. This is by no means an exclusively border effect, as there are many examples in the innovation literature of undesirable or unexpected segmentations emerging and hindering innovation. This may be between different functions within a firm (e.g. R\&D, manufacturing, marketing) that shape the way that innovation projects are planned, between competing R\&D teams, or reflecting personal factions within the group. The greatest problem they may cause in the planning phase are opportunistic decisions to take the project in a suboptimal way because achieving the optimal resource allocation would require blending activities between sites spanning the border.

As for the fourth proposition - although epistemic communities differ, cognitive proximity can as bridging mechanism - we found that firms did not really experience working with cross-border partners as being different from working with domestic partners. They were aware of some differences and did report differences that can be related to language, norms and values and business culture, but this did not heavily influence the collaborative innovation process. As we hypothesized it seems to be that a certain level of cognitive proximity, in this case mainly between engineers in high tech fields, is enough for a smooth cooperation process.

Interpreting this as a more general border blocking it is clear that the majority of the cross-border effects might better be understood as international collaboration effects that have a particular manifestation because of the geographical local nature of the distant partner. In the specific case of the Dutch-Belgian border, there is a popular discourse around cultural dissonances across the border. What was interesting in this case was that one factor that is sometimes cited as a problem (the directness of the Dutch business culture to Belgian sensitivities, Vogels, 2015) was actually a positive factor in indicating a real innovation problem (in this case the aesthetic shortcomings of a user interface). 


\section{Discussions and conclusions}

In this paper, we have sought to answer the overarching research question of how the presence of a border affects the processes by which firms attempt to build up productive co-operations for innovation. Drawing on a case study of cross-border innovating firms in the Dutch-Flemish border region, we have been able to distinguish a number of border blocking effects on innovations. The dominant effects appear to be different at each stage of attempting to build up cross border innovation networks. We contend that there is no reason that these effects may not be evident in other kinds of innovation context.

Therefore we explore in this final section how we might understand these border blocking effects more generally, distinguishing four kinds of effect, viz. network-breaking, rationality bounding, structural separating and internationalisation effects. On that basis we reflect on what the general implications of this for academics seeking to understand how borders affect economic practices in the knowledge economy.

\section{Typologising border blocking effects on innovation}

In the preceding section, we can see that there is a clear evolution in the nature of the border effect, with its blocking effects reducing over the phases, and potential benefit effects increasing. We here distinguish the apparently dominant effect at each phase of the innovation collaboration process as respectively the network breaking effect, the rationality bounding effect, a structural separating effect and an internationalisation effect.

In the first phase, it has a network breaking effect, preventing knowledge overspills, both through an absence of cross-border networks, but also the difficulties in developing second order contacts across the border via existing contacts. In making an internal decision to seek external resources, potential assets located across the border are not considered simply because they lie without the firms' cognitive field.

Once the decision to cross the border has been taken, the border has a rationality bounding effect; in taking a 'good enough' decision about prospective collaboration partners, a border raises the costs of getting information on locally-located firms and therefore makes it harder for them to be fairly included in the consideration. This is arguably where two kinds of border blocking effects are strongest (and beneficial effects 
are weakest). Firstly, firms start their search in their direct surroundings, mainly regional and national, and appear to mentally exclude proximate foreign firms from consideration once an adequate national partner is identified. Secondly, there seems to be a lack of network connections with firms or other organizations across the border, increasing the costs of gaining information on proximate foreign firms.

In the third phase, the set-up of the project, the border can have a structural separating effect, encouraging partners to create working structures which do not reflect the optimal knowledge community dynamics, but rather that follow the existing organisational lines across the border. In the final phase, the border reverts to having an internationalisation effect, creating uncertainties and differences, but also offering potentials and solutions for firms that have the skills to exploit them.

\section{Conclusions}

In this paper we have explored cross-border blocking effects as a way of asking a more general question about the unpredictability of border regions. Given the apparently massive latent potential for resource sharing in border spaces, why do firms facing their own resources not try to access those resources across borders. But this question is a way of addressing a broader phenomenon in border regions which is why the persistence of choice to look inwards rather than over the border despite apparent substantial incentives for so doing. In dealing with that more general issue, we would note that particularly in economic literature - there has been a tendency to reduce the border in a binary way, as something that either blocks interaction or does not, rather than as a gateway which is more or less accessable. A typical heuristic of a cross-border regional innovation system (for example Lundquist and Triple, 2011), sees an evolution from no connections to dense connections as corresponding with a kind of disappearance of the border. To this we would make two contributions.

Firstly, the border effect is in our perspective no simple binary, either blocking or not, rather it has effects that evolve as connections build up (operator latent potential is not activated). Borders create, divide and split in unexpected places, in the ways that firms can draw on their extended networks (network-breaking), in firms' cognitive fields in decision-making (rationality bounding), and also in the structures by which learning activities are planned (structural separating). These effects may block innovation, but as the case study showed, they shape the way that innovation collaboration takes place. 
Our second contribution is to suggest that these effects may not be limited to attempts to develop novel cross-border innovation networks, but may also be evident in a range of cross-border network activities. Our approach regards the development of networks as an evolutionary process in which actors make efforts that are shaped by circumstances that in turn alter the environments in which actors are located. The fact that there is not a simple dissolution of the border means that these feedback loops in conjunction with these qualitatively different border effects may lead to unexpected outcomes. Given that it has proven difficult to stimulate many different kinds of border co-operations - far more than would appear rational given the potential to unlock latent opportunities - these different effects, and their interplays from a dynamic perspective may provide new perspectives and tools for understanding the complex dynamics of these cross-border spaces. 


\section{REFERENCES}

AMIN, A. \& P. COHENDET (2004), Architectures of knowledge: Firms, capabilities and communities. Oxford: Oxford University Press.

BARNEY, J. B., \& D.N. CLARK (2007). Resource-based theory: Creating and sustaining competitive advantage. Oxford: Oxford University Press.

BATHELT, H., \& P. TURI (2011). Local, global and virtual buzz: The importance of face-to-face contact in economic interaction and possibilities to go beyond. Geoforum, 42(5), 520-529.

DYER, J. H., \& H. SINGH (1998). A relational perspective. The Academy of Management Review, $23(4), 660-679$.

FAGERBERG, J. (2006). Innovation: A Guide to the Literature. In J. Fagerberg, D. C. Mowery, \& R. R. Nelson (Eds.), The Oxford Handbook of Innovation (pp. 1-26). Oxford: Oxford University Press.

GERTNER, D., J. ROBERTS \& D. CHARLES (2011). University-industry collaboration: a CoPs approach to KTPs. Journal of Knowledge Management, 15(4), 625-647.

GRANT, R. M. (2002). The knowledge-based view of the firm. In C. W. Choo \& N. Bontis (Eds.), The strategic management of intellectual capital and organizational knowledge (pp. 133148). New York: Oxford University Press

HAHN, C. K. (2013). The transboundary automotive region of Saar-Lor-Lux: Political fantasy or economic reality? Geoforum, 48, 102-113.

HASELSBERGER, B., \& P.BENNEWORTH (2011). Cross-border communities or cross-border proximity? Perspectives from the Austrian- Slovakian border region. In N. Adams, G. Cotella, \& R. Nunes (Eds.), Territorial Development, Cohesion and Spatial Planning (pp. 229254). New York: Routledge.

HASSINK, R., \& C. KLAERDING (2012). The End of the Learning Region as We Knew It; Towards Learning in Space. Regional Studies, 46(8), 1055-1066.

KALE, P., H. SINGH \& H. PERLMUTTER (2000). Learning and protection of proprietary assets in strategic alliances: Building relational capital. Strategic Management Journal, 21, 217 - 237.

KIM, C.-S., \& A.C. INKPEN (2005). Cross-border R\&D alliances, absorptive capacity and technology learning. Journal of International Management, 11(3), 313-329.

KLATT, M., \& H.HERRMANN (2011). Half Empty or Half Full? Over 30 Years of Regional CrossBorder Cooperation Within the EU: Experiences at the Dutch-German and Danish-German Border. Journal of Borderlands Studies, 26(1), 65-87.

KNOBEN, J., \& L.A.G. OERLEMANS (2012). Configurations of Inter-organizational Knowledge Links: Does Spatial Embeddedness Still Matter? Regional Studies, 46(8), 1005-1021.

KOEN, C. (2011). Collaborative Innovation in High-Technology Sectors. Tilburg: Tilburg University. 
KOSCHATZKY, K. (2000). A river is a river - Cross-Border Networking Between Baden and Alsace. European Planning Studies, 8(4), 429-449.

KRÄTKE, S. (1999). Regional Integration or Fragmentation? The German-Polish Border Region in a New Europe. Regional Studies, 33(7), 631-641.

LEICK, B. (2012). Business Networks in the Cross-border Regions of the Enlarged EU: What do we know in the Post-enlargement Era? Journal of Borderlands Studies, 27(3), 299-314.

LOFGREN, O. (2008). Regionauts: the Transformation of Cross-Border Regions in Scandinavia. European Urban and Regional Studies, 15(3), 195-209.

MARSHALL, D., R. MCIVOR \& R. LAMMING (2007). Influences and outcomes of outsourcing: Insights from the telecommunications industry. Journal of Purchasing and Supply Management, 13(4), 245-260.

MARXT, C., \& P.LINK (2002). Success factors for cooperative ventures in innovation and production systems. International Journal of Production Economics, 77, 219-229.

MOULAERT, F., \& FSEKIA (2003). Territorial innovation models: a critical survey. Regional Studies, 37(3), 289-302.

NELSON, R. R., \& S.G.WINTER (1982). An evolutionary theory of economic change. Cambridge, Massachusetts: The Belknap Press of Harvard University Press.

NIELSEN, B. B. (2004). The role of trust in collaborative relationships: A multi-dimensional approach.M@n@gement, 7(3), 239-256.

OECD. (2013). Regions and Innovation: Collaborating Across Borders (OECD Revie). Paris: OECD Publishing.

PAASI, A., \& PROKKOLA, E. K. (2008). Territorial dynamics, cross-border work and everyday life in the Finnish-Swedish border area. Space and Polity, 12(1), 13-29.

REVILLA DIEZ, J., \& M. KIESE (2009). Regional innovation systems. In International Encyclopedia of Human Geography (pp. 246-251). Amsterdam Elsevier.

STENSHEIM, I. (2012). R\&D practices and communities in the TNC--proximities and distances. Journal of Economic Geography, 12(3), 651-666.

TORRE, A. (2008). On the Role Played by Temporary Geographical Proximity in Knowledge Transmission. Regional Studies, 42(6), 869-889.

TRIPPL, M. (2010). Developing Cross-Border Regional Innovation Systems: Key Factors and Challenges. Tijdschrift Voor Economische En Sociale Geografie, 101(2), 150-160.

UZZI, B. (1997), Social structure and competition in interfirm networks: The paradox of embeddedness. Administrative Science Quarterly, 42 (1): 35-67.

VAN HOUTUM, H. (1998). The development of cross-border economic relations. Tilburg: Tilburg University Press. 
VAN HOUTUM, H., O.T. KRAMSCH \& W. ZIERHOFER (2005). B/ordering space. Aldershot: Ashgate.

VOGELS, P. (2015) “Botte Ollanders, Timide Belgen” De Twentsche Courant Tubantia 13 May 2015 p. 13 
The Center for Higher Education Policy Studies (CHEPS) is a research institute (WHW, Article 9.20) located in the Faculty of Behavioural and Management Scienes within the University of Twente, a public university established by the Dutch government in 1961. CHEPS is a specialized higher education policy centre that combines basic and applied research with education, training and consultancy activities.

http://www.utwente.nl/bms/cheps/

$|c| h|l| p|s|$

Center for

Higher Education

Policy Studies 